\title{
ATTENUATION OF TOP-DOWN AND BOTTOM-UP FORCES IN A COMPLEX TERRESTRIAL COMMUNITY
}

\author{
DANIEL S. GRUNER ${ }^{1}$ \\ University of Hawaii at Manoa, Department of Zoology and Ecology, Evolution and Conservation Biology Program, \\ 2538 The Mall/Edmondson Hall, Honolulu, Hawaii 96822 USA
}

\begin{abstract}
Carnivore (top-down) and resource (bottom-up) influences in food webs are strong and pervasive, but few studies have investigated their interactive effects in speciesrich terrestrial ecosystems. This study focused on arthropods associated with the dominant tree species, Metrosideros polymorpha (Myrtaceae), in Hawaiian forests. Severe soil nutrient limitation on a 120-yr-old lava flow was removed by fertilization and combined with bird predator exclusion cages in a randomized block design. Arthropod densities were measured from clipped foliage at the outset and conclusion of a 33-mo experiment, and their biomass was estimated using regression equations. Metrosideros foliar nitrogen, tree growth, and biomass increased directly in response to fertilization but did not change with bird exclusion. Fertilization increased detritivore densities but not biomass, and both density and biomass of herbivores, while bird exclusion increased both density and biomass of carnivores. Fertilization also increased spider density and biomass, but bird exclusion increased spider numbers (15 species) only in high resource plots. Overall, trophic level biomass responses were less pronounced than density because smaller bodied individuals responded more to enrichment. Bottom-up factors controlled basal trophic levels, and detritivores comprised the largest fraction of arthropod density and biomass. Conversely, topdown impacts were apparent but variable, limited to higher order consumers, and did not cascade to the level of primary producers. These experimental results were consistent with the view that complex forest ecosystems are structured on a bottom-up template.
\end{abstract}

Key words: Arthropoda; bottom-up and top-down processes; fertilization; Hawaiian Islands; insectivorous birds; Metrosideros polymorpha; predator exclusion; spiders; terrestrial food web; tropical island montane forest.

\section{INTRODUCTION}

Theoretical models of trophic interactions predict that the intensity of consumer control in food webs depends on potential productivity (Oksanen et al. 1981, Abrams 1993, Moore et al. 2003). Numerous aquatic studies have examined if and how predation ("topdown") and resource ("bottom-up") constraints interact to determine densities and biomass of mid trophic level species (Osenberg and Mittelbach 1996). In terrestrial systems, vertebrate predators can have large impacts on species-rich arthropod communities with indirect effects propagated to primary producers (e.g., Marquis and Whelan 1994, Van Bael et al. 2003), but top-down factors are often contingent on strong bottom-up influences (e.g., Sipura 1999, Ritchie 2000). This suggests that bottom-up forces determine the maximum productivity and range of possibilities in an ecosystem, while top-down forces govern details of realized growth and structure (Gutierrez et al. 1994).

Several recent reviews and metaanalyses assert that top-down trophic cascades are more widespread in ter-

Manuscript received 01 January 2004; revised 4 April 2004; accepted 22 April 2004. Corresponding Editor: D. A. Spiller.

${ }^{1}$ Present address: Bodega Marine Laboratory, P.O. Box 247, Bodega Bay, California 94923-0247 USA. E-mail: dsgruner@ucdavis.edu restrial ecosystems than previously thought (Pace et al. 1999, Schmitz et al. 2000, Halaj and Wise 2001, Walker and Jones 2001). These reviews draw on literature demonstrating strong top-down indirect effects in both temperate (e.g., Marquis and Whelan 1994) and tropical systems (e.g., Dyer and Letourneau 1999), but come primarily from agroecosystems and grasslands, often restricted to a single species of plant, herbivore, and predator. However, many terrestrial food webs are reticulate, with heterogeneous weak interactions dampening cascading indirect effects among nonadjacent levels (Polis and Strong 1996, McCann et al. 1998, Neutel et al. 2002). Interactions among species pairs, perhaps clear and consistent in isolation, can display unpredictable behavior, changing intensity or even direction of interactions when combined with additional species (Wootton 1994). Thus, it is not clear if linear food chain models and strong cascading indirect effects are germane to species-rich communities.

Few terrestrial studies have attempted to partition the relative impacts of top-down and bottom-up forces among speciose trophic levels or feeding guilds (but see Forkner and Hunter 2000). The original green world (Hairston et al. 1960) and ecosystem exploitation hypotheses (Oksanen et al. 1981) refer to community, ecosystem, or larger scale biomass patterns. Moreover, when trophic cascades are defined precisely to include 


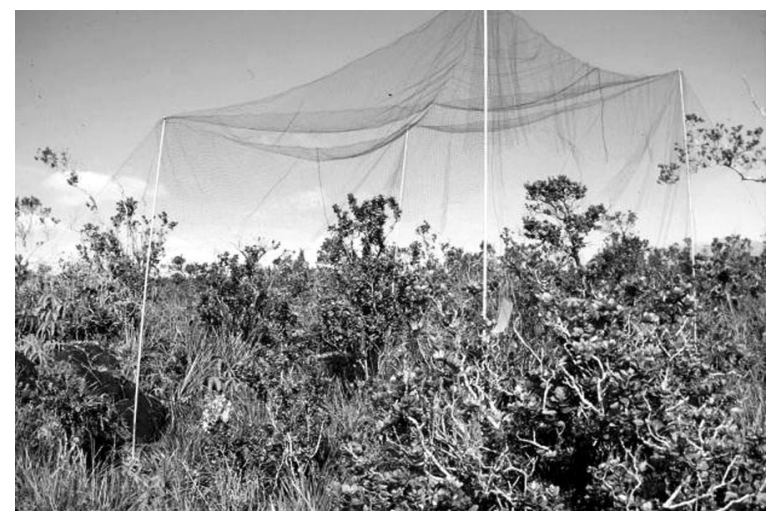

Plate. 1. A bird exclusion cage on an unfertilized plot on the 1881 lava flow, Mauna Loa, Hawai 'i, in March 2001 (see Appendix A for a color version). Photo credit: D. S. Gruner.

only predator-mediated indirect effects on biomass of producer standing crop (Hunter 2001), they appear less common and weaker in terrestrial than aquatic systems (Shurin et al. 2002). Community-level cascading indirect effects may represent emergent properties unpredictable through studies of pairwise interactions (Persson 1999, Polis 1999; but see Schmitz and SokolHessner 2002). Due to logistical difficulties of manipulating communities at appropriate temporal and spatial scales, experimental studies from terrestrial ecosystems examining plant biomass responses to predators are scarce, more so for tropical systems.

Here I describe a 33-mo manipulation of the resources and avian predators of an arboreal arthropod food web in the Hawaiian Islands. Two principal questions were addressed in this study. (1) What are the relative influences of top-down and bottom-up forces on trophic-level biomass and abundance of the $\mathrm{Me}$ trosideros polymorpha ecosystem? And (2) do the impacts of avian predators cascade to affect primary producer biomass via intermediate level consumers? In accord with theoretical predictions (Oksanen et al. 1981, Moore et al. 2003) and empirical findings (e.g., Gutierrez et al. 1994, Uriarte and Schmitz 1998, Forkner and Hunter 2000, Moran and Scheidler 2002), I predicted that resource limitation would be pervasive, but expected that greater bird response or recruitment, and subsequent top-down impacts, would occur only under enriched nutrient conditions. Because of the complexity of this food web, cascading influences of birds on biomass or growth of $M$. polymorpha were not expected. Furthermore, the experimental results ought to differ according to trophic group or feeding guild. I predicted increased biomass and abundance of all trophic groups with fertilization, but with stronger impacts on primary consumers (herbivores and detritivores) than on carnivores. Bird exclusion was expected to influence carnivores and herbivores, but not detritivores, consistent with bird diet studies (Perkins
1903, Baldwin 1953; C. Ralph and C. J. Ralph, unpublished data). Finally, I estimated the relative strength of top-down and bottom-up forces and compared these effect sizes to those of other systems (Shurin et al. 2002).

\section{Methods}

\section{Site descriptions and study species}

The experiments were located on a basaltic lava flow of the pãhoehoe morphology dated to 1881 in the Upper Waiãkea Forest Reserve, on the windward slope of Mauna Loa, Island of Hawai 'i (see Plate 1; $19.6642^{\circ}$ $\mathrm{N}, 19.2817^{\circ} \mathrm{W} ; \sim 1200 \mathrm{~m} ; 4000 \mathrm{~mm}$ mean annual precipitation; Giambelluca et al. 1986). Soils at this site are thin, patchy, and extremely nutrient limited, especially by nitrogen $(\mathrm{N})$, responding to fertilizer addition with up to a 10-fold increase in photosynthesis and net primary productivity (Raich et al. 1996). 'Ōhi 'a lehua (Metrosideros polymorpha Gaudichaud-Beaupré: Myrtaceae) dominates native forests from sea level to $2400 \mathrm{~m}$ (Dawson and Stemmerman 1990), and is the first woody colonist and most abundant species on recent lava flows. Although trees are of short stature (2$3 \mathrm{~m}$ ) in open canopies, Metrosideros is a key contributor to ecosystem biomass and productivity (Raich et al. 1997, Herbert and Fownes 1999). A variety of shrubs, herbs, ferns, and fern allies are also present at the site, the most abundant of which are Dicranopteris linearis (Burm.) Underw. (Gleicheniaceae), Machaerina angustifolia (Gaud.) T. Koyama (Cyperaeae), Coprosma ernodeoides A. Gray (Rubiaceae), Vaccinium spp. (Ericaceae), and Palhinhaea cernua (L.) Franco \& Crav. Vasc. (Lycopodiaceae).

The fauna associated with Metrosideros in Hawaii is limited to arthropods and birds. Metrosideros polymorpha is attacked by multiple guilds of herbivorous insects, including several families of leaf-chewing Lepidopteran larvae, phloem- and xylem-feeding Heteroptera and Homoptera, gall-forming psyllids (Homoptera: Triozidae), and wood-boring coleopteran larvae (Swezey 1954, Gagné 1979, Stein 1983). Invertebrate predators (e.g., Araneae, Heteroptera: Nabidae), hymenopteran parasitoids (e.g., Ichneumonidae, Bethyliidae, and Chalcidoidea), and litter processors, fungal grazers, and scavengers (e.g., Psocoptera, Isopoda, Collembola, some Coleoptera) are abundant within tree canopies.

Six passerines were observed at the site, three of which were relatively common: the native 'apapane (Himatione sanguinea) and 'oma'o (Myadestes obscurus), and the introduced Japanese White-Eye (Zosterops japonicus). Zosterops japonicus is predominantly insectivorous, $H$. sanguinea nectarivorous, and $M$. obscurus frugivorous, but foraging observations and stomach, crop, gizzard, and fecal samples indicate yearround opportunistic insectivory by all species, and a greater reliance on arthropods while provisioning nests 
in the spring (Perkins 1903, Baldwin 1953, van Riper and Scott 1979; C. Ralph and C. J. Ralph, unpublished data). The insectivorous 'amakihi (Hemignathus virens virens) and 'elepaio (Chasiempis sandwichensis) and the nectarivorous ' $\mathrm{i}$ 'iwi (Vestiaria coccinea) were observed less frequently. All species were more abundant within nearby forests on more developed soils (personal observation).

\section{Experimental design}

The experiment was a randomized block design, with fertilization and avian predator exclusion as crossed, fixed factors. Thirty-two $400 \mathrm{~m}^{2}$ plots were laid out in pairs along a transect with buffer strips $10 \mathrm{~m}$ wide, at minimum, separating all plots. Adjacent pairs were then grouped into 8 blocks of 4 plots each. The transect bearing $\left(245^{\circ}\right)$ was determined by aerial photographs to closely parallel the edge of mature forest on older substrate of greater soil fertility, which provided an allocthonous pool of foraging birds. Before assigning treatments to plots, I randomly selected for observational focus a tree or clump of trees (1-6 individuals) from all possible clumps within the central $8 \times 8 \mathrm{~m}$ of each plot. Clumps were defined by one or more trees at least $2 \mathrm{~m}$ tall, but not taller than $3.5 \mathrm{~m}$. Trees taller than $4 \mathrm{~m}$ were unusual, but were excluded from consideration for logistical reasons. All other trees were included within a clump if it could be confined within a cage. There were a total of 88 focal trees distributed among 32 plots in 8 blocks along a modest elevational gradient $(\sim 100 \mathrm{~m})$.

Within each of the blocks, one of four treatments was assigned randomly to each plot: (1) control, (2) fertilization only, (3) bird exclusion cage only, and (4) fertilization and cage. Fertilization treatments consisted of semiannual hand broadcast of granular essential nutrients following the "NPT" protocol of Raich et al. (1996) designed to alleviate severe nutrient limitation. This regime produces soil and foliar nutrient levels within the natural range of variation found at sites throughout the islands (Crews et al. 1995, Raich et al. 1996). Beginning in September 1998, N (1/2 ammonium nitrate and $1 / 2$ urea), $\mathrm{P}, \mathrm{K}, \mathrm{Ca}$, and a micronutrient mix each were spread at a level of $100 \mathrm{~kg} / \mathrm{ha}$, and $\mathrm{Mg}$ was applied at a level of $50 \mathrm{~kg} / \mathrm{ha}$. Later applications were half the initial level. The final fertilization occurred in October 2000.

Bird exclosure cages were constructed (4 $\mathrm{m}$ tall $\times$ 4-6 m each side) with sheer UV-resistant polypropylene mesh $(2 \times 2 \mathrm{~cm}$; Easy Gardener, Waco, Texas, USA) draped over lightweight aluminum conduit piping (4 m high) slotted on steel rebar pounded into the basalt substrate (Appendix A). Galvanized wire was strung between poles and as guy wire to rebar anchors. Openings in the mesh were stitched together and secured to the ground to minimize gaps. Insects pass freely through this mesh, but birds are excluded completely (the smallest bird at the site, Z. japonicus, is
10-12 cm in length [van Riper 2000]). In previous studies, bird exclosure cages with similar-sized mesh had no impacts on microclimate parameters such as rainfall, temperature in full sun, and temperature in shade (Bock et al. 1992).

\section{Plant variables}

Leaves were collected from each focal tree for the measurement of foliar $\mathrm{N}$ and leaf mass/area on four occasions: at the start and conclusion of the experiment, and after 10 and 22 mo (the $1 / 3$ and $2 / 3$ points in the experiment, respectively). Haphazard collections of 36 whorls of mature sun leaves represented the existing range of height, cardinal position, and relative size. Whorls with herbivore damage were avoided, as were branches tagged for an ongoing herbivory study. A total of 8-19 leaves were selected randomly from each tree, the petioles were clipped, and leaves were measured for area while fresh $\left( \pm 0.01 \mathrm{~cm}^{2}\right)$. Leaves were dried to constant mass at $65^{\circ} \mathrm{C}$ (at least $48 \mathrm{~h}$ ), weighed $( \pm 0.001 \mathrm{~g})$, hand crushed and homogenized, and analyzed by automated Kjeldahl digestion and colorimetric methods for percent total $\mathrm{N}$ per leaf dry mass (Agricultural Diagnostic Service Center, Department of Agronomy and Soil Science, University of Hawaii).

Basal area and height of the 88 focal trees on the plots were measured prior to the application of treatments and at 6-mo intervals until study conclusion. Since it was not possible to measure diameter at breast height for these small trees, basal area was estimated as the sum of the area of all stems larger than $2 \mathrm{~cm}$ in diameter above the root crown. All diameter measurements were taken from the same point marked with a small nail. Tree height was measured from the ground $( \pm 0.05 \mathrm{~m})$, and calibrated to the position of the nail because of the uneven surface (Raich et al. 1996). Total tree foliage biomass was estimated from basal area and height with regressions generated from one $M$. polymorpha data set (Gerrish 1990), and corroborated with independent data (Raich et al. 1997).

\section{Arthropod sampling and analysis}

Arthropods were sampled by branch clipping before the application of the experimental treatments (25-28 August 1998) and at the study conclusion (16 April-3 May 2001). Branch clipping enables absolute population estimates of both sessile and mobile taxa associated with trees and potentially available to canopy foraging birds (Basset et al. 1997, Johnson 2000). The final collection period coincided with the nesting and fledging period of the most common passerines at the site (Baldwin 1953, Ralph and Fancy 1994), a time when avian demand for arthropods should be high, but preceding expected declines in some arthropods over the summer (unpublished data). The terminal ( $\sim 50 \mathrm{~cm}$ ) twigs and foliage, the primary microhabitat exploited by many insectivorous birds in the Hawaiian Islands and the locus of highest arthropod concentrations (Fretz 
2000), were clipped into doubled white plastic garbage bags. I selected 5-10 branches haphazardly from the full range of heights and compass bearings available for each plant. Reproductive structures (seeds, flowers) were avoided. Extreme care was exercised in avoiding disturbance before branches were quickly bagged and clipped.

Foliage was collected in the morning hours, in one randomly selected block per day, and transported to the laboratory at Kilauea Field Station, Hawai 'i Volcanoes National Park, for immediate processing. Foliage was shaken and beaten onto a white cloth, and arthropods were collected with an aspirator and stored in $70 \%$ ethanol. I continued shaking branches until no additional arthropods were observed, sifted the detrital remainder for arthropods, and oven dried the vegetation. Foliage was separated from wood, re-dried to constant mass, and both components weighed to $\mathrm{mg}$ precision.

All arthropods were counted, measured to mm length classes, and identified to species or morphospecies, and assigned to one of four trophic groups: carnivores, detritivores, herbivores, and tourists. Feeding assignments were based on personal observation, literature review, and communication with systematists. Carnivores include all spiders, cursorial hunters, and parasitoids; detritivores comprise saprophagic arthropods and grazers of litter, fungi, and microbes; herbivores consist of sap feeders, gall formers (mostly free-living adults), wood borers, and foliage chewers; and tourists include species known to be incidental or nonfeeding on Metrosideros, or with unknown or highly omnivorous feeding habits. Taxonomic groups also were classified as potential prey based on bird foraging observations and stomach, crop, gizzard, and fecal samples of passerine birds known from the site (Perkins 1903, Baldwin 1953; C. Ralph and C. J. Ralph, unpublished data). Prey items generally included Araneae, Diptera, Homoptera, Lepidoptera, and Psocoptera $>1.5 \mathrm{~mm}$ in body length, while most Acari, Coleoptera, Collembola, Heteroptera, Hymenoptera, Isopoda, and all arthropods $<1.5 \mathrm{~mm}$ long were treated as nonprey items. Biomass was calculated using regression relationships of body morphometrics to dry mass (Gruner 2003). Arthropod abundance and biomass are reported per $100 \mathrm{~g}$ dry foliage mass ("load," sensu Root 1973); analyses of abundance or biomass per unit leaf area gave similar results and are not reported.

Specimen data were managed with the biodiversity collections database software, Biota (Colwell 1997). Specimens are deposited at the B. P. Bishop Museum, Honolulu, Hawaii.

\section{Statistical analyses}

Data were analyzed with mixed general linear models (GLM) with type III sums of squares, treating fertilization and bird exclusion as fixed factors. The block term was treated as random and included all two-way interactions in accordance with model 1 of Newman et al. (1997). Block interactions were included because the effect of fertilization may vary spatially with heterogeneity in the lava substrate texture (Raich et al. 1996), while distance from adjoining older substrates, augmentative source pools of nesting and foraging birds, may result in heterogeneous responses to the cage effect. In this model, each fixed main effect was tested using the mean square of its interaction with the block factor, rather than the mean squared error, as the denominator of the $F$ ratio (Newman et al. 1997). In the cases where qualitative results differ from models without block interactive effects, full models were the more conservative tests of the null hypotheses. The statistical software SAS was used for all analyses (SAS 2001).

A regression approach was used to estimate $M$. polymorpha foliage biomass from height and basal area measurements. Using data from Gerrish (1990), a power equation was the most useful predictive model for dry leaf biomass in grams $\left(R^{2}=0.957, n=12, P<\right.$ $0.001)$. Predictions from this model were tightly congruent to actual foliar biomass measured in an independent data set (final foliar dry mass: $r=0.989, n=$ $88, P<0.001$; Raich et al. 1997). Although initial tree height, basal area, and foliar biomass did not differ significantly among treatments, there was a trend towards larger trees randomly assigned to caged treatments. Thus, I calculated the relative growth (RG) of plant morphometric variables, which factors the initial plant size into the analysis of final size $\left(\ln X_{t 1}-\ln X_{t 0}\right)$. Plot means of RG values were analyzed using the mixed model GLM.

Because foliar $\mathrm{N}$ results from the same trees over time were not independent, this response was tested with a repeated-measures analysis. Between-subjects main effects and two-way interactions were tested as in the previous GLM model, with the addition of within-subjects interactions with time. The arcsine transformation (Zar 1999) for percentage foliar N met normality assumptions.

Final arthropod collections data were analyzed using initial collections as a fixed covariate in the GLM design, but as the covariate was never significant, initial and final collections were analyzed in separate GLMs. To avoid lending equal weight to trees of different sizes, arthropod totals and clipped foliage mass for all trees were summed to create load estimates for each plot. Natural log transformation on plot totals was necessary and sufficient to meet assumptions of normality and homoscedasticity for all arthropod variables. Separate GLMs were run for individual trophic levels: carnivores, herbivores, and detritivores, for bird prey vs. nonprey classifications, and numerically important taxonomic groups. Tourists represented $<1 \%$ of total abundance and biomass, and were not explored further. Post hoc multiple comparisons, using the joint significance level of $\alpha=0.05$, were run for each GLM using Tukey's hsd. There were no qualitative differences in 
GLM results from those estimated with maximum likelihood procedures for mixed model designs (Saavedra and Douglass 2002) using PROC MIXED (SAS 2001), and only the least squares results are reported.

The multivariate response of all trophic levels were tested using the MANOVA procedure of PROC GLM (SAS 2001). To test if each group differed from the others in their response to treatments, trophic pairs were contrasted using profile analysis on the fertilization and caging factors and their interaction. Wilks' lambda was used for all hypothesis tests, but it did not differ appreciably from other $F$ ratio estimations (e.g., Pillai's trace).

To compare the magnitude of top-down and bottomup effects, I estimated the $\log$ response ratio $(L)$ and $95 \%$ confidence intervals for the effects of treatments on $M$. polymorpha foliar biomass relative growth rate (effect size $L=\ln \left[N_{\mathrm{EXP}} / N_{\mathrm{CTRL}}\right]$; Hedges et al. 1999, Shurin et al. 2002). There is some debate whether these estimates should include a temporal component $(\Delta r=$ $L / t$; Osenberg et al. 1997). This experimental duration is among the longest published factorial manipulations of top-down and bottom-up processes (Shurin et al. 2002, Bell et al. 2003), and it is likely that new equilibrium conditions are reached. This assumption was evaluated by plotting biomass $\mathrm{RG} \log$ ratios over all 6-mo measurement intervals. Log response ratios were computed for final density and biomass of arthropod detritivores, herbivores, and carnivores, and for prey and nonprey arthropods. As there were no significant interactions between fertilization and bird exclusion in the GLM analysis for any of these arthropod variables, all replicates $(n=16)$ for the two main effects were used to calculate the ratios $\left(L_{\mathrm{TD}}=\ln \left[N_{(\mathrm{CAGE}+\mathrm{BOTH})} /\right.\right.$ $\left.\left.N_{\text {(FERT }+ \text { CTRL) }}\right] ; L_{\mathrm{BU}}=\ln \left[N_{\text {(FERT }+ \text { BOTH })} / N_{(\mathrm{CAGE}+\mathrm{CTRL})}\right]\right)$. An index of relative effect strength (relative effect size $=$ $\ln \left[\left|L_{\mathrm{BU}}\right| /\left|L_{\mathrm{TD}}\right|\right]$; Denno et al. 2003) quantified these comparisons (see Fig. 3).

\section{RESUlTS}

\section{Plant variables}

The fertilization treatments positively influenced the growth and foliage quality of Metrosideros polymorpha.The growth response of the vegetation was dramatic, with many new flushes on $M$. polymorpha trees, and increased biomass of the surrounding plant community, but with no apparent vegetation changes in response to the cages.

As with the analysis of basal area and height alone (basal area RG: $F_{1,7}=73.96, P<0.001$; height RG: $\left.F_{1,7}=60.84, P<0.001\right)$, only fertilization changed final $M$. polymorpha foliar biomass $\left(F_{1,7}=38.65, P<\right.$ $0.001)$. Trees grew larger and more rapidly when fertilized, with growth rates peaking after $1 \mathrm{yr}$, while unfertilized trees did not add biomass over $2.5 \mathrm{yr}$ (overall means, leaf biomass change $\pm 1 \mathrm{SE}, n=16$; unfertilized $=89.5 \pm 114.4 \mathrm{~g}$; fertilized $=1408.2 \pm 201.5 \mathrm{~g}) . \mathrm{Log}$

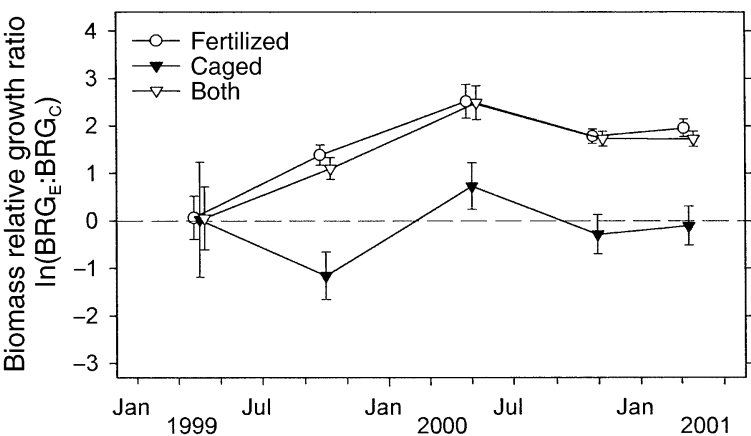

FIG. 1. Effect sizes $\left(\log _{e}\right.$ ratio, $\left.\ln \left[\mathrm{BRG}_{\mathrm{E}}: \mathrm{BRG}_{\mathrm{C}}\right]\right)$ of fertilization, bird exclusion, and the fertilization $\times$ exclusion treatments on $M$. polymorpha foliar biomass relative growth. Estimates are calculated from the difference in the means of the treatments $\left(\mathrm{BRG}_{\mathrm{E}}\right)$ and the control $\left(\mathrm{BRG}_{\mathrm{C}}\right)$. Errors represent $\pm 1 \mathrm{SE}$, calculated with the variance equations of Hedges et al. (1999). The dashed line represents no difference of experimental means from control means. $\mathrm{BRG}=$ biomass relative growth.

response ratios of biomass relative growth in fertilized treatments peaked and stabilized after $1 \mathrm{yr}$, and caging did not alter this pattern (Fig. 1). Log ratios were not adjusted for temporal scale because estimates appear to level at equilibrium over the final two sampling periods. The cage-only treatments initially responded negatively, rebounded to a positive $\log$ ratio after $1 \mathrm{yr}$, then stabilized at no net effect. Final effect sizes ( $\pm 95 \% \mathrm{CI})$ on Metrosideros biomass were estimated as follows: fertilized $=1.95 \pm 1.1$; cage $=-0.11 \pm$ 2.3 ; both $=1.92 \pm 1.1$.

Fertilization increased foliar $\mathrm{N}$ (fertilized: $F_{1,7}=$ $44.25, P<0.001$ ), but no other between-subjects factor was significant. Within-subjects, time was strongly significant (time: $F_{3,21}=154.91, P<0.0001$ ), as was its interaction with fertilization and with the block term (time $\times$ fertilization: $F_{3,21}=54.179, P<0.0001$; time $\times$ block: $\left.F_{3,21}=2.284, P<0.033\right)$. Foliar $\mathrm{N}$ was elevated $25-30 \%$ after one year and remained at that level for the duration of the experiment (final pooled mean \pm SE, unfertilized: $0.58 \pm 0.02 \%$; fertilized: $0.80 \pm$ $0.02 \%)$.

\section{Arthropod densities and biomass}

Prior to the application of experimental treatments in August 1998, there were no differences in overall arthropod abundance (total arthropods $=2894$; overall mean/100 g foliage $\pm \mathrm{SE}=49.0 \pm 3.6)$ and biomass (overall $\mathrm{mg} / 100 \mathrm{~g}$ foliage $\pm \mathrm{SE}=19.06 \pm 3.1$ ), or in trophic level abundance and biomass among blocks or treatments.

A total of 16354 arthropods were collected at the conclusion of the study in April and May of 2001. Foliage collections were larger than initial samples because there were no limitations with the destructive clipping method. After 33 mo, densities in control plots were comparable to initial levels (mean abundance/100 


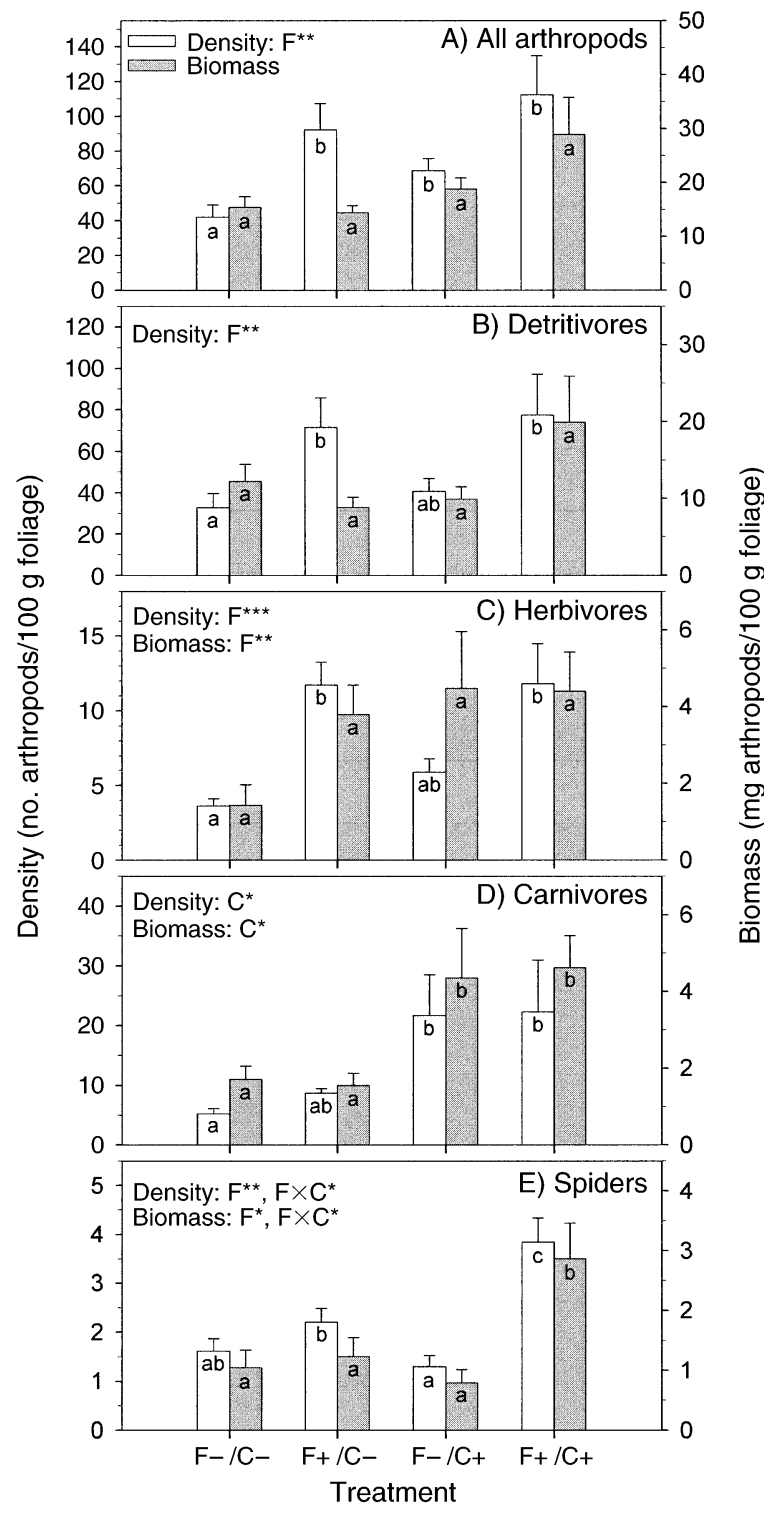

FIG. 2. Mean density (open bars) and biomass (gray bars) of arthropods in response to fertilization ("F") and bird exclusion ("C" = cage) treatments: (A) all arthropods, (B) detritivores, (C) herbivores, (D) carnivores, and (E) spiders. Spider data exclude Achaearanea cf. riparia. Note the differing scales of arthropod variables, measured as a function of dry foliage biomass, for each grouping. Error bars represent +1 SE. Fixed effects from GLM analysis (Appendix B) are listed if significant $(* 0.05>P>0.01 ; * * 0.01>P$ $>0.001 ; * * * 0.001>P$ ). Bars with different lowercase letters denote significantly different comparisons within response variables tested by Tukey's hsd. ( joint $\alpha=0.05$ ).

$\mathrm{g}$ foliage $=42.2 \pm 6.9$ ), while both fertilization and cage treatments increased densities (Fig. 2A, Appendix $B)$. Although the cage main effect and cage $\times$ fertilization interactions were only marginally significant $(0.10>P>0.05)$, the cage factor was significant in the reduced model dropping nonsignificant block interactions $\left(F_{1,21}=5.499, P=0.029\right)$. The block factor was also significant in both models, indicating spatial heterogeneity in arthropod abundance (Appendix B). However, treatment differences apparent for total arthropod density disappeared when considering biomass load. Although total arthropod biomass appeared elevated in the combined fertilized and caged treatment (Fig. 2A), this increase was accompanied by elevated variability, and no factors were statistically significant (Appendix B). Moreover, there were no significant correlations among trophic level biomass loads. MANOVA and profile analyses revealed generally similar but weaker trends. For density, the fertilization effect is significant, with a marginal, positive trend of the cage treatment, whereas no factors are significant for arthropod biomass (Appendix C).

There were clear differences in the responses of different trophic groups to the experimental treatments (Fig. 2). Fertilization increased detritivore densities, but neither caging nor the treatment interaction was significantly different (Fig. 2B, Appendix B). Detritivore densities varied among blocks, generally decreasing with elevation, or some factor correlated with elevation (linear regression, $R^{2}=0.793$, $\mathrm{df}=7, P=$ 0.003). However, all effects were nonsignificant for detritivore biomass (Appendix B). Numerically, smallbodied Collembola were the dominant group of detritivores responding to fertilization and block factors (fertilized $F_{1,7}=10.110, P=0.016$; block: $F_{7,7}=$ 3.154, $P=0.076$ ). Collembola biomass also responded positively to fertilization treatments (fertilized: $F_{1,7}=$ 6.334, $P=0.040$ ), but the biomass of the large-bodied and mobile isopod Porcellio scaber Latreille (Porcellionidae) was unchanged (all $F$ tests not significant).

Herbivore density and biomass increased with fertilization, but no other factors were statistically significant in the GLM analysis (Fig. 2C, Appendix B). As with detritivores, herbivore densities in both fertilized treatments were distinct from controls, but not significantly different than caged treatments. Herbivore biomass appeared elevated in all three treatments relative to the control, but these differences were not significant due to high variability (Fig 2C). Herbivore and detritivore densities correlated strongly and positively $(r=0.777, \mathrm{df}=30, P<0.0005)$, but biomass did not ( $r=0.129, P=0.483)$.

Bird exclusion alone elevated carnivore abundance and biomass (Fig. 2D, Appendix B). The response of carnivores to bird exclusion was attributable to spiders, numerically the most dominant group of invertebrate carnivores in the system (cage: $F_{1,7}=18.538, P=$ 0.004). A single spider species, the introduced Achaearanea cf. riparia (Theridiidae), irrupted in abundance 25 -fold to 80 -fold in caged plots compared to uncaged plots (Gruner 2005). The bird exclusion effect on biomass varied across blocks (cage $\times$ block interaction) because of the variable presence of $A$. riparia outbreaks in the absence of predation. Because of its disproportionate influence, I removed this single 


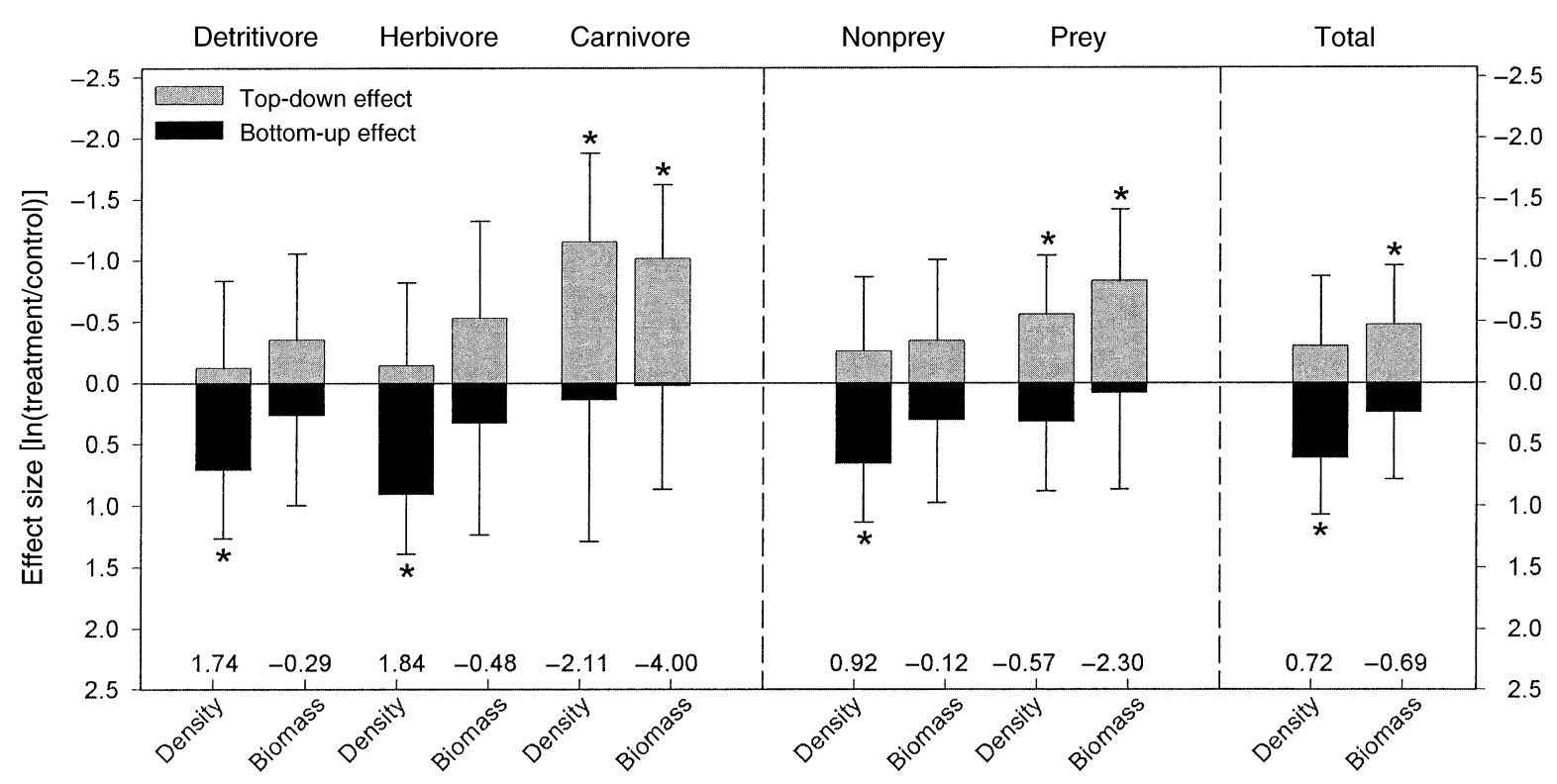

FIG. 3. Effect sizes ( $\log _{e}$ ratio) of top-down (insectivorous bird predation) and bottom-up (resources) forces on Metrosideros arthropods. $\log _{\mathrm{e}}$ ratios of top-down effects are the top gray bars, and solid bars below the zero line represent bottom-up effects. Errors represent 95\% confidence intervals; an asterisk above or below bars indicates confidence intervals not overlapping zero. Signs of log ratios from bird exclusion are changed from positive to negative to indicate the impact of bird presence. Numbers above the abscissa represent the magnitude of bottom-up relative to the top-down main effects (relative effect size $=\ln \left[\mid\right.$ effect $\operatorname{size}_{\mathrm{BU}}|:|$ effect size $\left.\mathrm{TD}_{\mathrm{TD}} \mid\right]$; Denno et al. 2003) on both density and biomass for trophic levels, prey and nonprey items, and all arthropods in sum. A positive value indicates a preponderance of bottom-up forces, a negative number specifies greater top-down effects, and a value of zero shows equal influence.

species and reanalyzed all remaining spiders (15 species) in a GLM (Appendix B). Bird exclusion alone did not change spider densities or biomass, while both fertilization and its interactive effect with caging emerged as significant for both density and biomass. Spiders (other than A. riparia) were most abundant on plots both fertilized and caged, intermediate on plots fertilized only, and lowest on unfertilized plots, caged or not (Fig. 2E). Predaceous arthropod numbers did not correlate with other trophic levels.

The heterogeneity of the top-down effect of birds across trophic groups was examined by dividing arthropods into categories of potential prey and nonprey items. The cage effect was highly significant for both prey density and biomass (density: $F_{1,7}=18.703, P=$ 0.003; biomass: $F_{1,7}=26.705, P=0.001$ ), but not for nonprey items (density: $F_{1,7}=4.336, P=0.076$; biomass: $F_{1,7}=1.379, P=0.448$ ). As with total arthropods, fertilization and block factors remained significant for nonprey density (fertilized: $F_{1,7}=13.307, P$ $=0.008$; block: $F_{1,7}=7.270, P=0.009$ ), but no factor was significant in the biomass model.

\section{Relative strengths of top-down vs. bottom-up forces}

I plotted the relative log ratios for top-down vs. bottom-up main effects on trophic levels, prey items, nonprey, and all arthropods combined (Fig. 3). Since the fertilization $\times$ cage interaction was not significant for any of these factors, those data were pooled into main effects. Bottom-up effects were stronger than top-down effects for primary consumers, nonprey arthropods, and for the community overall (Fig. 3). Top-down effects dominated for invertebrate carnivores and taxa common in bird diets. Across all categories, bottom-up effects usually were stronger than top-down effects for arthropod density, while the opposite was true for biomass. The pattern of the overall community was qualitatively similar to results for detritivores and nonprey items, each of which comprise the majority of individuals and biomass within their respective categories (Fig. 3). Smaller bodied individuals responded disproportionately to fertilization (Appendix D), but the topdown effect was stronger for total community biomass, influenced by responses of large bodied insects and spiders to bird exclusion. All arthropod log response ratios are presented in Appendix E.

\section{DISCUSSION}

Although birds reduced the numbers and biomass of spiders, this effect did not propagate to $M$. polymorpha standing crop or growth, either under low or high resource conditions (Fig. 1). Bottom-up forces impacted basal trophic levels strongly but top-down effects were more influential to higher order consumers. These factors acted independently, with the sole exception that birds limited the spider assemblage only in fertilized treatments (Fig. 2E). In this forested ecosystem, low productivity and abiotic stress, strong detrital flows, 
heterogeneity within and among trophic levels, inefficient generalist predators, and compensatory interactions decoupled bottom-up and top-down forces to eliminate cascading indirect effects.

\section{Nutrient limitation and detrital shunts}

Among terrestrial systems, top-down cascades are more frequent and stronger in productive, unstressed ecosystems, on small plants with high nutrient levels (Shurin et al. 2002). In general, forest ecosystems have slower turnover of nutrients and biomass than grasslands (Scheu and Setälä 2002), where most terrestrial trophic cascades have been reported (Halaj and Wise 2001). Primary productivity on a nearby, slightly older substrate $(145 \mathrm{yr})$, was estimated at $\sim 300 \mathrm{~g} \cdot \mathrm{m}^{-2} \mathrm{yr}^{-1}$ (Raich et al. 1997), substantially lower than the typical range for tropical forests (Clark et al. 2001) and the average for terrestrial systems worldwide (Field et al. 1998). Moreover, new basaltic substrates are physiologically stressful (sensu Menge and Sutherland 1987), with shallow and patchy soils that undergo rapid fluxes in moisture content (Raich et al. 1996). Waterlogging at poorly drained sites, as is common with the pâhoehoe lava morphology, can be a proximate cause of standlevel Metrosideros dieback (Akashi and Mueller-Dombois 1995).

Fertilization treatments alleviated nutrient limitation and enhanced $M$. polymorpha growth and foliage quality for primary consumers. Foliar $\mathrm{N}$ concentrations were consistently higher with fertilization. Nitrogen is the most common nutrient limiting primary production in terrestrial ecosystems and may be the "critical resource underpinning productivity gradients for insect herbivores" (Ritchie 2000). At sites on substrate of comparable composition and age, complete spectrum fertilization, as in this study, elevated primary productivity 10 -fold, increased $M$. polymorpha foliar concentrations of $\mathrm{N}, \mathrm{P}, \mathrm{K}$, and $\mathrm{Mg}$, and reduced the mass percentage of lignin (Raich et al. 1996, Vitousek 1998). Lignin deters or slows insect feeding on plants (Coley and Aide 1991), is digested very slowly, and only by fungi and microbes (Melillo et al. 1982). Metrosideros litter decomposability correlates inversely with initial lignin levels and positively to foliar N (Austin and Vitousek 2000, Hobbie and Vitousek 2000).

These trends favored increases of both herbivorous and detritivorous arthropods in response to fertilization (Fig. 2B, C; see Appendices). In this Metrosideros community, herbivores were comprised largely of sap suckers in several homopteran and heteropteran families. Although there are conflicting hypotheses for plant allocation of increased mineral resources (Stamp 2003), and numerous contradictory findings (Hamilton et al. 2001), fertilization more often benefited populations of phloem- or xylem-feeding insects on trees than leaf chewers (Kytö et al. 1996; see also Lightfoot and Whitford 1987, Boyer et al. 2003). Nevertheless, detritivorous arthropods were dominant in abundance and biomass (Fig. 2), suggesting that most available energy shunts directly to decomposers (Polis and Strong 1996). Top-down cascading effects are observed infrequently in detrital systems (Halaj and Wise 2001, Scheu and Setälä 2002, Moore et al. 2003).

\section{Abundance and body size}

Although detritivores, particularly Salina celebensis (Schaeffer) (Collembola: Entomobryidae), increased on fertilized trees at this site, fertilization had no effect on their total biomass (Fig. 2B). Regression procedures to estimate biomass, rather than direct measurement, may result in reduced precision and fewer biomass effects. However, in a fertilized prairie system where arthropods were weighed directly, arthropod biomass also showed fewer treatment effects than numerical variables (Kirchner 1977). As predicted by Hutchinson (1959), individuals of numerically dominant species in the present system weighed less than rare species in all treatments. Smaller bodied Collembola and juvenile phloem- and xylem-feeding Homoptera responded strongly to fertilization, and were relatively more abundant in fertilized treatments (Appendix D). The biomass effects of increased Collembola abundances were swamped by variable responses of mobile, large detritivores (e.g., Porcellio scaber). Boyer et al. (2003) observed a similar effect with large grasshoppers in a fertilized grassland.

When arthropods were grouped as potential prey on the basis of size and taxonomic characteristics reported from diet studies, the top-down factor dominated effect sizes in the prey subset, while the converse was true for arthropods deemed less vulnerable to birds (Fig. 3). However, birds had a proportionally greater effect on prey biomass, which translated to dominance of topdown forces on total arthropod biomass. For biomass, the top-down effect was generally stronger than the bottom-up effect (Fig. 3), despite fewer significant biomass responses in GLM analyses (Appendix B). The reverse pattern was apparent for density and for nonprey arthropod biomass. This suggests that birds had a disproportionate impact on large arthropods, whereas bottom-up influences dominated for smaller arthropods, and for density overall.

\section{Top-down heterogeneity and predator efficiency}

Detritivore and herbivore density and biomass were unaffected by the exclusion of avian predators, despite increased arthropod abundance in fertilized plots (Fig. 2). Many herbivorous taxa (e.g., Homoptera, Lepidoptera larvae) were found commonly in the diets of passerine birds in the region, while detritivores, with the exception of Psocoptera, were not (Perkins 1903, Baldwin 1953; C. Ralph and C. J. Ralph, unpublished data). Nevertheless, cage effects were not significant for herbivores (Fig. 2C, Appendix A), and log response ratios demonstrated a negative impact of birds on herbivores (cage only, inverse log ratio $\pm \mathrm{SD}=-0.486 \pm 0.205$ ), 
lower than values reported from other terrestrial systems (Shurin et al. 2002) with either vertebrate (mean $\log$ ratio $\pm \mathrm{SD}=-1.04 \pm 1.56$ ) or invertebrate carnivores $(-0.72 \pm 0.92)$. The weak top-down effects on herbivores in this system may be explained by the preponderance of endophagous species (e.g., gall formers, bud miners) that are virtually immune to avian predation in their immature stages. In addition, it is possible that compensatory predation by increasing populations of enemies released by bird exclusion mitigated any positive effects on herbivore populations (Pacala and Roughgarden 1984; but see Spiller and Schoener 1994).

The estimated changes in arthropod loads due to fertilization may be conservative from an avian standpoint. Load variables, relative to foliar biomass, were measured at the scale most appropriate for comparing population and community dynamics of arthropod prey. However, fertilized plots showed tree growth rates an order of magnitude higher and standing biomass more than double that of unfertilized plots (Fig. 1). Due to the larger individual tree size, increased foliage density, and increased density and biomass of prey (Fig. 3 ), fertilization increased absolute arthropod numbers per unit ground area, which may be the most appropriate scale for evaluating resource availability for insectivorous birds (Fretz 2002). Rough estimates of abundance and biomass at larger spatial scales were extrapolated using the product of final arthropod loads and estimated tree foliar biomass. Although plant demographic data were not measured on the basis of ground area, total arthropod abundance increased 2.7fold and biomass was 1.9 times higher on a per tree basis in fertilized plots (abundance: $F_{1,7}=39.46, P=$ 0.0004; biomass: $\left.F_{1,7}=11.96, P=0.011\right)$. This effect was also strongly significant for detritivores and herbivores, but was only a marginal effect for carnivore density $(P=0.037)$ and a positive trend for carnivore biomass and for spiders $(0.05<P<0.10)$.

As expected, no cascading top-down effects of insectivorous bird predation on plant biomass or growth were observed. Consistent with some trophic dynamic theory (Oksanen et al. 1981, Moore et al. 2003), abundance of top predators (insectivorous birds) was lower at this unproductive site than in mature forest, possibly regulated by limited resource supply. Fretz (2000) documented a strong positive interannual correlation among reproductive success of two native insectivorous passerines and $M$. polymorpha arthropod abundance over three years. This, in addition to evidence for interspecific competition among Japanese WhiteEyes and several native passerines, including 'elepaio, 'amakihi and 'i'iwi, suggests that arthropod food resources were limiting for birds in some habitats and times (Mountainspring and Scott 1985). I predicted that birds would recruit to increased vegetation complexity and arthropod abundance on fertilized plots, thus increasing top-down effects in these treatments. Anec- dotally, more birds and bird species were observed in fertilized plots, but structural differences in vegetation among fertilization treatments biased all attempts to census and compare bird densities. Community effects of this prediction generally were not supported, as cage and fertilization treatments interacted only within the spider assemblage, exclusive of A. riparia (Fig. 2E).

Bioenergetic models, coupled with diet selection and arthropod abundance studies, in steppe ecosystems (Rotenberry 1980) predict that avian generalists are functionally insignificant, "inefficient" insectivores (sensu Power 1992) that will not exhibit top-down control. If birds focus their efforts on restricted taxa within arthropod communities, however, their impact may be greater than predicted by these models. For instance, leaf-chewing Lepidoptera larvae were by far the most common herbivores in an oak sapling system, and exclusion of birds led to increased herbivory to the oaks (Marquis and Whelan 1994). In a similar system without cascading indirect effects, the herbivore community was more varied (Lichtenberg and Lichtenberg 2002). In Hawaiian systems, Baldwin (1953) augmented diet analyses of forest birds with field estimates of prey availability on dominant plant species. Although some taxa appeared to be avoided or ignored (e.g., heteropterans, isopods), he found that most prey types were taken in proportion to their field availability, a pattern consistent with donor control (DeAngelis 1980, Chase 1996). In the present study, however, birds did have an impact on carnivores, particularly spiders (Fig. 2). When likely prey items from other trophic levels are considered, however, a significant negative effect of birds is maintained (Fig. 3). These data reveal within and between trophic-level heterogeneity (Hunter and Price 1992), muting indirect effects that might otherwise propagate in linear fashion among adjacent trophic levels down the food web (McCann et al. 1998, Neutel et al. 2002). Examples where birds exhibit strong top-down control and indirect effects on producers may involve less heterogeneity or birds with more selectivity on key taxa.

\section{Compensatory indirect interactions}

Overall, nutrient augmentation did not cascade up to the aggregate level of invertebrate natural enemies, but enemy densities increased an order of magnitude in the absence of birds (Fig. 2D). This effect was less pronounced but still apparent for carnivore biomass (Fig. $2 \mathrm{H})$. Upon closer examination of the composition of the carnivore trophic level, the effect was attributable to spiders. Araneae were among the three most abundant prey items for all five bird species for which there were sufficient fecal samples (C. Ralph and C. J. Ralph, unpublished data) and may be the most important prey items for Hawaiian passerines in general (Perkins 1903, Baldwin 1953). Other exclusion studies of birds have shown marked effects on spiders (Askenmo et al. 1977, Gunnarsson 1996, Evelegh et al. 2001, Van Bael et al. 
2003). Unlike many herbivorous taxa, which can sequester toxic secondary compounds from their food resources, spiders are usually undefended chemically and are favored prey to vertebrates (Oxford and Gillespie 1998).

The effect of bird exclusion was particularly pronounced on one introduced species (Theridiidae: Achaearanea cf. riparia) that irrupted in the absence of birds (Gruner 2005). The strong numerical response of Achaearanea cf. riparia to bird exclusion was driven by large aggregations of juvenile spiders (Gruner 2005), which may have resulted from the escape of small numbers of females from bird predation. While A. riparia has not been studied in this habitat, tangleweb theridiids generalize on mobile arthropods (e.g., Collembola) but probably do not regulate their prey populations (Wise 1993). Neither densities nor biomass of this spider correlated with numbers of other major groups.

The irruption of $A$. riparia masked a significant fertilization $\times$ cage interactive effect on the remaining spider assemblage (Fig. 2E). Spider numbers cascaded up in fertilized plots with birds present, but the effect nearly doubled in their absence. Bird predation and resource limitation acted in compensatory fashion, showing some support for the hypothesis that top predator control is mediated by productivity (Gutierrez et al. 1994). In resource-limited environments, spiderspider interactions may be more intense, with intraguild predation or competition for prey or space negating their release from bird predation (Rypstra 1983, Spiller 1984). Fertilization caused a dramatic vegetation response, concomitantly increasing shade, humidity, and abundance of living and dead plant material, both in litter and suspended in the canopy. Increased vegetation complexity may reduce abiotic stressors (Wise 1993), increase hunting or prey capture efficiency (Riechert and Bishop 1990, Halaj et al. 2000), or may protect spiders from other foraging predators, such as birds and other spiders (Gunnarsson 1990, Finke and Denno 2002). Alternatively, spiders may benefit from increases in herbivorous and detritivorous insects in fertilized plots (Chen and Wise 1999, Denno et al. 2002, Miyashita et al. 2003) and reduced competition for those resources (Spiller 1984).

\section{Conclusions}

Trophic levels are artificial conceptualizations (Persson 1999) that subsume ecological processes, such as omnivory and intraguild predation, found to be prevalent in terrestrial food webs (Coll and Guershon 2002). However, in this complex community comprising $>100$ species (Appendix F), trophic-level analyses revealed biologically explicable differences in response to bottom-up and top-down forces. Bottom-up forces predominated for both trophic levels directly consuming primary productivity (living and dead), while top-down effects influenced predaceous arthropods most strongly
(McQueen et al. 1986, 1989). These factors appeared to compensate and dissipate, rather than propagate (Pace et al. 1999), within the assemblage of generalist, inefficient spider predators.

\section{ACKNOWLEDGMENTS}

I thank the Division of Forestry and Wildlife, State of Hawaii, for field research permits and access. I am grateful to G. Bodner, R. Cabin, S. Cordell, L. Durand, N. Everett, D. Feinholz, P. Hart, S. Hight, R. Langston, P. Nilsson, and especially K. Heckmann, L. Wilson, S. McDaniel, and E. McDaniels for providing invaluable technical assistance, and D. Foote for logistical assistance. C. and C. J. Ralph shared unpublished data, A. Taylor offered statistical advice, and with J. Ewel, M. Moran, R. Forkner, D. Spiller, M. Hunter, E. Preisser, and one anonymous reviewer, improved the manuscript with critical comments. This work was supported by an EPA S.T.A.R. predoctoral fellowship, grants from Sigma $\mathrm{Xi}$, the Hawaii Audubon Society, the Watson T. Yoshimoto Foundation, the ARCS Foundation, NSF DDIG (DEB0073055), and by training grants from the John D. and Catherine T. MacArthur Foundation, and NSF grants DGE9355055 and DUE-9979656 to the Center for Conservation Research and Training at the University of Hawaii.

\section{Literature Cited}

Abrams, P. A. 1993. Effect of increased productivity on the abundances of trophic levels. American Naturalist 141: 351-371.

Akashi, Y., and D. Mueller-Dombois. 1995. A landscape perspective of the Hawaiian rain forest dieback. Journal of Vegetation Science 6:449-464.

Askenmo, C., A. von Bromssen, J. Ekman, and C. Jansson. 1977. Impact of some wintering birds on spider abundance in spruce. Oikos 28:90-94.

Austin, A. T., and P. M. Vitousek. 2000. Precipitation, decomposition and litter decomposability of Metrosiderous polymorpha in native forests on Hawaii. Journal of Ecology 88:129-138.

Baldwin, P. H. 1953. Annual cycle, environment and evolution in the Hawaiian honeycreepers (Aves: Drepaniidae). University of California Publications in Zoology 52:285398.

Basset, Y., N. D. Springate, H. P. Aberlenc, and G. Delvare. 1997. A review of methods for sampling arthropods in tree canopies. Pages 27-52 in N. E. Stork, J. Adis, and R. K. Didham, editors. Canopy Arthropods. Chapman and Hall, London.

Bell, T., W. E. Neill, and D. Schluter. 2003. The effect of temporal scale on the outcome of trophic cascade experiments. Oecologia 134:578-586.

Bock, C. E., J. H. Bock, and M. C. Grant. 1992. Effects of bird predation on grasshopper densities in an Arizona grassland. Ecology 73:1706-1717.

Boyer, A. G., R. E. Swearingen, M. A. Blaha, C. T. Fortson, S. K. Gremillion, K. A. Osborn, and M. D. Moran. 2003. Seasonal variation in top-down and bottom-up processes in a grassland arthropod community. Oecologia 136:309316.

Chase, J. M. 1996. Abiotic controls of trophic cascades in a simple grassland food chain. Oikos 77:495-506.

Chen, B., and D. H. Wise. 1999. Bottom-up limitation of predaceous arthropods in a detritius-based terrestrial food web. Ecology 80:761-772.

Clark, D. A., S. Brown, D. W. Kicklighter, J. Q. Chambers, J. R. Thomlinson, J. Ni, and E. A. Holland. 2001. Net primary production in tropical forests: an evaluation and synthesis of existing field data. Ecological Applications 11: 371-384. 
Coley, P. D., and T. M. Aide. 1991. Comparison of herbivory and plant defenses in temperate and tropical broad-leaved forests. Pages 25-49 in P. W. Price, T. M. Lewinsohn, G. W. Fernandes, and W. W. Benson, editors. Plant-animal interactions: evolutionary ecology in tropical and temperate regions. Wiley, New York, New York, USA.

Coll, M., and M. Guershon. 2002. Omnivory in terrestrial arthropods: mixing plant and prey diets. Annual Review of Entomology 47:267-297.

Colwell, R. K. 1997. Biota: the Biodiversity Database Manager, 1.0 edition. Sinauer Associates, Sunderland, MA.

Crews, T. E., K. Kitayama, J. H. Fownes, R. H. Riley, D. A Herbert, D. Mueller-Dombois, and P. M. Vitousek. 1995. Changes in soil phosphorus fractions and ecosystem dynamics across a long chronosequence in Hawaii. Ecology 76:1407-1424.

Dawson, J. W., and L. Stemmerman. 1990. Metrosideros (Myrtaceae). Pages 964-970 in W. L. Wagner, D. R. Herbst, and S. H. Sohmer, editors. Manual of the flowering plants of Hawaii. Bernice P Bishop Museum Press, Honolulu, Hawaii, USA.

DeAngelis, D. L. 1980. Energy flow, nutrient cycling, and ecosystem resilience. Ecology 61:764-771.

Denno, R. F., C. Gratton, H. Döbel, and D. L. Finke. 2003. Predation risk affects relative strength of top-down and bottom-up impacts on insect herbivores. Ecology 84:10321044.

Denno, R. F., C. Gratton, M. A. Peterson, G. A. Langellotto, D. L. Finke, and A. F. Huberty. 2002. Bottom-up forces mediate natural-enemy impact in a phytophagous insect community. Ecology 83:1443-1458.

Dyer, L. A., and D. K. Letourneau. 1999. Trophic cascades in a complex terrestrial community. Proceedings National Academy Sciences USA 96:5072-5076.

Evelegh, N. C. P., J. D. Majer, and H. F. Recher. 2001. The effects of reducing bird predation on canopy arthropods of marri (Eucalyptus calophylla) saplings on the Swan Coastal Plain, Western Australia. Journal of the Royal Society of Western Australia 84:13-21.

Field, C. B., M. J. Behrenfeld, J. T. Randerson, and P. Falkowski. 1998. Primary production of the biosphere: integrating terrestrial and oceanic components. Science 281: 237-240.

Finke, D. L., and R. F. Denno. 2002. Intraguild predation diminished in complex-structured vegetation: implications for prey suppression. Ecology 83:643-652.

Forkner, R. E., and M. D. Hunter. 2000. What goes up must come down? Nutrient addition and predation pressure on oak herbivores. Ecology 81:1588-1600.

Fretz, J. S. 2000. Relationship of canopy arthropod prey to distribution and life history of the Hawai' $i$ 'akepa. Dissertation. University of Hawaii at Manoa, Honolulu, Hawaii, USA.

Fretz, J. S. 2002. Scales of food availability for an endangered insectivore, the Hawaii akepa. Auk 119:166-174.

Gagné, W. C. 1979. Canopy-associated arthropods in Acacia koa and Metrosideros tree communities along an altitudinal transect on Hawaii island. Pacific Insects 21:56-82.

Gerrish, G. 1990. Relating carbon allocation patterns to tree senescence in Metrosideros forests. Ecology 71:11761184.

Giambelluca, T. W., M. A. Nullet, and T. A. Schroeder. 1986. Rainfall atlas of Hawaii. Department of Land and Natural Resources, State of Hawaii, Honolulu, Hawaii, USA.

Gruner, D. S. 2003. Regressions of length and width to predict arthropod biomass in the Hawaiian Islands. Pacific Science 57:325-336.

Gruner, D. S. 2005. Biotic resistance to an invasive spider conferred by generalist insectivorous birds on Hawai 'i Island. Biological Invasions 7, in press.
Gunnarsson, B. 1990. Vegetation structure and the abundance and size distributions of spruce-living spiders. Journal of Animal Ecology 59:743-752.

Gunnarsson, B. 1996. Bird predation and vegetation structure affecting spruce-living arthropods in a temperate forest. Journal of Animal Ecology 65:389-397.

Gutierrez, A. P., N. J. Mills, S. J. Schreiber, and C. K. Ellis. 1994. A physiologically based tritrophic perspective on bottom-up-top-down regulation of populations. Ecology 75:2227-2242.

Hairston, N. G., F. E. Smith, and L. B. Slobodkin. 1960. Community structure, population control, and competition. American Naturalist 94:421-425.

Halaj, J., A. B. Cady, and G. W. Uetz. 2000. Modular habitat refugia enhance generalist predators and lower plant damage in soybeans. Environmental Entomology 29:383-393.

Halaj, J., and D. H. Wise. 2001. Terrestrial trophic cascades: how much do they trickle? American Naturalist 157:262281.

Hamilton, J. G., A. R. Zangerl, E. H. DeLucia, and M. R. Berenbaum. 2001. The carbon-nutrient balance hypothesis: its rise and fall. Ecology Letters 4:86-95.

Hedges, L. V., J. Gurevitch, and P. S. Curtis. 1999. The metaanalysis of response ratios in experimental ecology. Ecology 80:1150-1156.

Herbert, D. A., and J. H. Fownes. 1999. Forest productivity and efficiency of resource use across a chronosequence of tropical montane soils. Ecosystems 2:242-254.

Hobbie, S. E., and P. M. Vitousek. 2000. Nutrient limitation of decomposition in Hawaiian forests. Ecology 81:18671877.

Hunter, M. D. 2001. Multiple approaches to estimating the relative importance of top-down and bottom-up forces on insect populations: experiments, life tables, and time-series analysis. Basic and Applied Ecology 2:295-309.

Hunter, M. D., and P. W. Price. 1992. Playing chutes and ladders: heterogeneity and the relative roles of bottom-up and top-down forces in natural communities. Ecology 73: $724-732$.

Hutchinson, G. E. 1959. Homage to Santa Rosalia, or why are there so many kinds of animals? American Naturalist 93: $145-159$.

Johnson, M. D. 2000. Evaluation of an arthropod sampling technique for measuring food availability for forest insectivorous birds. Journal of Field Ornithology 71:88-109.

Kirchner, T. B. 1977. The effects of resource enrichment on the diversity of plants and arthropods in a shortgrass prairie. Ecology 58:1334-1344.

Kytö, M., P. Niemela, and S. Larsson. 1996. Insects on trees: population and individual response to fertilization. Oikos 75:148-159.

Lichtenberg, J. S., and D. A. Lichtenberg. 2002. Weak trophic interactions among birds, insects and white oak saplings (Quercus alba). American Midland Naturalist 148:338349.

Lightfoot, D. C., and W. G. Whitford. 1987. Variation in insect densities on desert creosotebush: is nitrogen a factor? Ecology 68:547-557.

Marquis, R. J., and C. J. Whelan. 1994. Insectivorous birds increase growth of white oak through consumption of leafchewing insects. Ecology 75:2007-2014.

McCann, K., A. Hastings, and G. R. Huxel. 1998. Weak trophic interactions and the balance of nature. Nature 395: 794-798.

McQueen, D. J., M. R. S. Johannes, J. R. Post, T. J. Stewart, and D. R. S. Lean. 1989. Bottom-up and top-down impacts on freshwater pelagic community structure. Ecological Monographs 59:289-309.

McQueen, D. J., J. R. Post, and E. L. Mills. 1986. Trophic relationships in freshwater pelagic ecosystems. Canadian Journal of Fisheries and Aquatic Science 43:1571-1581. 
Melillo, J. M., J. D. Aber, and J. F. Muratore. 1982. Nitrogen and lignin control of hardwood leaf litter decomposition dynamics. Ecology 63:621-626.

Menge, B. A., and J. P. Sutherland. 1987. Community regulation: variation in disturbance, competition, and predation in relation to environmental stress and recruitment. American Naturalist 130:730-757.

Miyashita, T., M. Takada, and A. Shimazaki. 2003. Experimental evidence that aboveground predators are sustained by underground detritivores. Oikos 103:31-36.

Moore, J. C., K. S. McCann, H. Setälä, and P. C. de Ruiter. 2003. Top-down is bottom-up: does predation in the rhizosphere regulate aboveground dynamics? Ecology 84: 846-857.

Moran, M. D., and A. R. Scheidler. 2002. Effects of nutrients and predators on an old-field food chain: interactions of top-down and bottom-up processes. Oikos 98:116-124.

Mountainspring, S., and J. M. Scott. 1985. Interspecific competition among Hawaiian forest birds. Ecological Monographs 55:219-239.

Neutel, A.-M., J. A. P. Heesterbeek, and P. C. de Ruiter. 2002. Stability in real food webs: weak links in long loops. Science 296: $1120-1123$.

Newman, J. A., J. Bergelson, and A. Grafen. 1997. Blocking factors and hypothesis tests in ecology: is your statistics text wrong? Ecology 78:1312-1320.

Oksanen, L., S. D. Fretwell, J. Arruda, and P. Niemela. 1981. Exploitation ecosystems in gradients of primary productivity. American Naturalist 118:240-261.

Osenberg, C. W., and G. G. Mittelbach. 1996. The relative importance of resource limitation and predator limitation in food chains. Pages 134-148 in G. A. Polis and K. O. Winemiller, editors. Food webs: integration of patterns and dynamics. Chapman and Hall, New York, New York, USA.

Osenberg, C. W., O. Sarnelle, and S. D. Cooper. 1997. Effect size in ecological experiments: the application of biological models in meta-analysis. American Naturalist 150:798812.

Oxford, G. S., and R. G. Gillespie. 1998. Evolution and ecology of spider coloration. Annual Review of Entomology 43:619-643

Pacala, S., and J. Roughgarden. 1984. Control of arthropod abundance by Anolis lizards on St. Eustatius (Neth. Antilles). Oecologia 64:160-162.

Pace, M. L., J. J. Cole, S. R. Carpenter, and J. F. Kitchell. 1999. Trophic cascades revealed in diverse ecosystems. Trends in Ecology and Evolution 14:483-488.

Perkins, R. C. L. 1903. Vertebrata. Pages 365-466 in D. Sharp, editor. Fauna Hawaiiensis. Cambridge University Press, Cambridge, UK.

Persson, L. 1999. Trophic cascades: abiding heterogeneity and the trophic level concept at the end of the road. Oikos 85:385-397.

Polis, G. A. 1999. Why are parts of the world green? Multiple factors control productivity and the distribution of biomass. Oikos 86:3-15.

Polis, G. A., and D. R. Strong. 1996. Food web complexity and community dynamics. American Naturalist 147:813846.

Power, M. E. 1992. Top-down and bottom-up forces in food webs: do plants have primacy? Ecology 73:733-746.

Raich, J. W., A. E. Russell, T. E. Crews, H. Farrington, and P. M. Vitousek. 1996. Both nitrogen and phosphorus limit plant production on young Hawaiian lava flows. Biogeochemistry 32:1-14.

Raich, J. W., A. E. Russell, and P. M. Vitousek. 1997. Primary productivity and ecosystem development along an elevational gradient on Mauna Loa, Hawai'i. Ecology 78:707721.
Ralph, C. J., and S. G. Fancy. 1994. Timing of breeding and molting in six species of Hawaiian honeycreepers. Condor 96: $151-161$.

Riechert, S. E., and L. Bishop. 1990. Prey control by an assemblage of generalist predators: spiders in garden test systems. Ecology 71:1441-1450.

Ritchie, M. E. 2000. Nitrogen limitation and trophic vs. abiotic influences on insect herbivores in a temperate grassland. Ecology 81:1601-1612.

Root, R. B. 1973. Organization of a plant-arthropod association in simple and diverse habitats: the fauna of collards (Brassica oleracea). Ecological Monographs 43:95-124.

Rotenberry, J. T. 1980. Bioenergetics and diet in a simple community of shrubsteppe birds. Oecologia 46:7-12.

Rypstra, A. L. 1983. The importance of food and space in limiting web-spider densities — a test using field enclosures. Oecologia 59:312-316.

Saavedra, F., and L. Douglass. 2002. Using mixed models in SAS for ecological analyses. Bulletin of the Ecological Society of America 83:180-182.

SAS. 2001. The SAS System for Windows, 8.02 edition. SAS Institute, Cary, N.C.

Scheu, S., and H. Setälä. 2002. Multitrophic interactions in decomposer food-webs. Pages 223-264 in T. Tscharntke and B. A. Hawkins, editors. Multitrophic level interactions. Cambridge University Press, Cambridge, UK.

Schmitz, O. J., P. A. Hambäck, and A. P. Beckerman. 2000. Trophic cascades in terrestrial systems: a review of the effects of carnivore removals on plants. American Naturalist 155:141-153.

Schmitz, O. J., and L. Sokol-Hessner. 2002. Linearity in the aggregate effects of multiple predators in a food web. Ecology Letters 5:168-172.

Shurin, J. B., E. T. Borer, E. W. Seabloom, K. Anderson, C. A. Blanchette, B. Broitman, S. D. Cooper, and B. S. Halpern. 2002. A cross-ecosystem comparison of the strength of trophic cascades. Ecology Letters 5:785-791.

Sipura, M. 1999. Tritrophic interactions: willows, herbivorous insects and insectivorous birds. Oecologia 121:537545.

Spiller, D. A. 1984. Competition between two spider species: experimental field study. Ecology 65:909-919.

Spiller, D. A., and T. W. Schoener. 1994. Effects of top and intermediate predators in a terrestrial food web. Ecology 75:182-196.

Stamp, N. 2003. Out of the quagmire of plant defense hypotheses. The Quarterly Review of Biology 78:23-55.

Stein, J. D. 1983. Insects infesting Acacia koa (Legumosae) and Metrosideros polymorpha (Myrtaceae) in Hawaii: an annotated list. Proceedings, Hawaiian Entomological Society 24:305-316.

Swezey, O. H. 1954. Forest entomology in Hawaii. Special Publication 76, Bishop Museum, Honolulu, Hawaii, USA.

Uriarte, M., and O. J. Schmitz. 1998. Trophic control across a natural productivity gradient with sap-feeding herbivores. Oikos 82:552-560.

Van Bael, S. A., J. D. Brawn, and S. K. Robinson. 2003. Birds defend trees from herbivores in a Neotropical forest canopy. Proceedings of the National Academy of Sciences of the USA 100:8304-8307.

van Riper, C., III, and J. M. Scott. 1979. Observations on distribution, diet, and breeding of the Hawaiian thrush. Condor 81:65-71.

van Riper, S. G. 2000. Japanese White-Eye, Zosterops japonicus (Passeriformes: Zosteropidae). Birds of North America number 487. American Ornithological Union, Washington, D.C., USA.

Vitousek, P. M. 1998. Foliar and litter nutrients, nutrient resorption, and decomposition in Hawaiian Metrosideros polymorpha. Ecosystems 1:401-407. 
Walker, M., and T. H. Jones. 2001. Relative roles of top-down and bottom-up forces in terrestrial tritrophic plant-insect herbivore-natural enemy systems. Oikos 93:177-187.

Wise, D. H. 1993. Spiders in ecological webs. Cambridge University Press, Cambridge, UK.
Wootton, J. T. 1994. The nature and consequences of indirect effects in ecological communities. Annual Review of Ecology and Systematics 25:443-466.

Zar, J. H. 1999. Biostatistical analysis. Prentice Hall, Upper Saddle River, New Jersey, USA.

\section{APPENDIX A}

A color version of Plate 1, showing a bird exclusion cage on an unfertilized plot on the 1881 lava flow, Mauna Loa, Hawai ‘i, in March 2001, is available in ESA's Electronic Data Archive: Ecological Archives E085-098-A1.

\section{APPENDIX B}

A table showing general linear model results for arthropod trophic density and biomass is available in ESA's Electronic Data Archive: Ecological Archives E085-098-A2.

\section{APPENDIX C}

A table showing multivariate ANOVA and profile analysis results for arthropod trophic density and biomass is available in ESA's Electronic Data Archive: Ecological Archives E085-098-A3.

\section{APPENDIX D}

A figure showing cumulative arthropod biomass frequency distributions by experimental treatment is available in ESA's Electronic Data Archive: Ecological Archives E085-098-A4.

\section{APPENDIX E}

Tables showing bottom-up and top-down effect sizes for arthropod trophic levels and taxonomic categories are available in ESA's Electronic Data Archive: Ecological Archives E085-098-A5.

\section{APPENDIX F}

A table showing taxonomic identity, biogeographic status, trophic group, and cumulative abundance by treatment of sampled arthropod species is available in ESA's Electronic Data Archive: Ecological Archives E085-098-A6. 